\title{
The relationship between house size and life cycle energy use: implications for building energy efficiency regulations
}

\author{
André Stephan $^{\mathrm{a}, 1}$, Robert H. Crawford ${ }^{\mathrm{a}}$
}

${ }^{a}$ Faculty of Architecture, Building and Planning, The University of Melbourne, Victoria 3010, Australia

${ }^{1}$ Corresponding Author

Tel: +61383445929

$+61452502855$

e-mail: andre.stephan@unimelb.edu.au

\section{Abstract}

The size of detached houses has significantly increased over the last decades in many countries. Larger houses have life cycle energy requirements due to their increased use of materials and larger area to heat, cool and light. Yet, most current building energy efficiency regulations fail to adequately capture the effect of house size.

This study quantifies the effect of house size on life cycle energy demand in order to inform future building energy efficiency regulations. It uses a parametric model of a typical detached house in Melbourne, Australia and varies its floor area from 100 to $392 \mathrm{~m}^{2}$ for four different household sizes. Both initial and recurrent embodied energy requirements are quantified using the comprehensive input-output-based hybrid analysis technique and all operational energy end-uses (thermal and nonthermal) are calculated in primary energy terms over 50 years.

Results show that life cycle energy use increases at a slower rate compared to house size. Expressing energy efficiency per $\mathrm{m}^{2}$ therefore systematically favours large houses while these actually having a much higher life cycle energy demand. Also, embodied energy represents $26-50 \%$ of the energy demand across all 360 variations. Building energy efficiency regulations should incorporate embodied energy, correct energy intensity levels for house size and use multiple functional unit to express energy efficiency. These measures will help achieve net energy reductions. 
House size; life cycle energy analysis; functional unit; embodied energy; sublinear correlation; household size.

\section{Introduction}

It is urgent to reduce greenhouse gas emissions from human activities in order to limit further major disruptions to the ecosystems and climate of the Earth. Already, the ten hottest years on record have occurred in the last 15 years [1]. The operation of buildings alone is responsible for more than a third of global final energy use and associated greenhouse gas emissions [2] and for much more if indirect energy use and emissions are accounted for [3]. Buildings have therefore a central role to play in mitigating climate change [4] and in paving the way towards a more resource efficient built environment.

Residential buildings constitute the largest share of the building stock and are responsible for most operational energy use within the building sector, as evidenced by studies such as Perez-Lombard et al. [5]. This has pushed many countries to enforce energy efficiency regulations. These often focus solely on thermal performance such as in Australia [6] through the 6-Star standard or in Europe [7] through the Energy Performance of Buildings Directive (EPBD). These regulations can help reduce operational energy use, notably when they consider primary energy use such as in the EPBD. However, one of the major drawbacks of building energy efficiency regulations is their lack of consideration of embodied energy. Indeed, they cannot result in a net reduction of energy use unless they consider the entire life cycle of the building by including its embodied energy, as demonstrated by a large number of studies, inter alia [8-10]. This disregard for embodied energy becomes even more significant when another core characteristic is considered: house size.

The size of a building is proportional to the amount of materials required for its construction, the associated embodied energy, as well as the surface area to heat, cool and light. While several studies have quantified the relationship between house size and operational energy (e.g.Clune et al. [11], Guerra Santin et al. [12], Wilson and Boehland [13] and Yohanis et al. [14]), very few have analysed the relationship between house size and life cycle energy use, i.e. Fuller and Treloar [15] and Fuller and Crawford [16]. The latter rely on a very small sample of different house sizes which are built to different specifications and are therefore not comparable. The relationship between house size and 
life cycle energy demand is therefore not well understood while it can significantly affect the effectiveness of building energy efficiency regulations for three main reasons.

Firstly, many countries have witnessed a significant increase in average house size over the last decades. In Australia, where houses are among the largest in the world, the average new house size was $241 \mathrm{~m}^{2}$ in 2012 [17] compared to $167 \mathrm{~m}^{2}$ in 1984 . Houses in the USA follow a similar increase in floor area over the same time period going from $163 \mathrm{~m}^{2}$ in 1984 to $215 \mathrm{~m}^{2}$ in 2012 (based on data from [18] and [19]). While standalone houses in France have also increased in size over the last 30 years, it is to a much lesser extent, going from $96 \mathrm{~m}^{2}$ in 1984 to $112 \mathrm{~m}^{2}$ in 2013 (based on data from [20] and [21]). These larger houses systematically require more materials and more operational energy. The increased operational energy efficiency from 1984 until today might have been offset by the increased need for heating and cooling as proposed by Calwell [22], and this is not accounting for the extra embodied energy in larger houses. House size should therefore be a main factor in any energy efficiency regulation. While there is a size correction factor in the Australian regulations, size is barely considered in the EPBD.

Secondly, the increase in house size over the last decades was paralleled by an average decrease in average household size according to the same sources. This combination results in a significant increase in the average floor area per capita and therefore in additional embodied energy per capita. For example, the average floor area per person in Australian new standalone houses went from $\sim 57$ $\mathrm{m}^{2} /$ capita in 1984 to $~ 94 \mathrm{~m}^{2} /$ capita in $2012(+65 \%$, based on $[17,23])$. This figure went from 33 $\mathrm{m}^{2} /$ capita to $44 \mathrm{~m}^{2} /$ capita in France over the same time period (+33\%, based on [20] and [21]). Given that the initial embodied energy of one square metre of floor area lies within 10-19 GJ (based on results from [24-27]), each Australian requires an additional 370-703 GJ in 2012 compared to 1984 for the increased floor area, or enough energy to drive around Australia $~ 8-15$ times (in a car with a fuel efficiency of $10 \mathrm{~L} / 100 \mathrm{~km}$, considering that the energy content of gasoline is $32.4 \mathrm{MJ} / \mathrm{L}$ and based on $14500 \mathrm{~km}$ per roundtrip). Capturing house size in life cycle energy analysis is therefore critical.

Thirdly, the relationship between house size and embodied energy is currently understudied. The majority of existing life cycle energy analysis studies provide results on a per square metre of gross or usable floor area basis [28-31]. While this metric theoretically allows the comparison of houses with different sizes, it is not clear how the embodied energy intensity increases with floor area as the 
internal walls per square metre tends to be lower in large houses as these have larger rooms. If embodied energy does not increase linearly with house size, this could mean that studies that use average embodied energy intensities per $\mathrm{m}^{2}$ to quantify embodied energy could be flawed as the embodied energy intensity will be tied to the original house size it was derived from. This study will help understand how embodied energy varies with house size.

\subsection{Aim and scope}

The aim of this paper is to quantify and understand the effect of house size on the life cycle energy demand in order to inform future building energy efficiency regulations that can effectively reduce total energy use.

The focus is on energy because it is a good proxy for other environmental impacts of buildings as demonstrated by studies in Finland [32], Belgium [33] and Spain [34].

The life cycle stages taken into account comprise raw material extraction, material manufacture, processing and transport, construction and operation and maintenance. The end-of-life stage is not taken into account because of the huge uncertainties regarding the fate of the building many decades into the future. Furthermore studies have shown that the end-of-life stage often represents less than $1 \%$ of the total life cycle energy demand, e.g. Winistorfer et al. [35]. This paper quantifies the embodied energy of all building materials (including all energy inputs across the entire supporting supply chains) as well as the operational energy used for heating, cooling, lighting, hot water, appliances and cooking. All results are expressed in primary energy terms.

\subsection{Structure}

This paper starts by reviewing existing studies on house size and energy use in Section 2 before describing the method and quantification algorithms used in Section 3. Section 4 presents the results which are discussed in Section 5 along with the contribution and limitations of the study. The conclusion is provided in Section 6.

\section{Existing studies on house size and energy use}

Few studies have investigated the relationship between house size and energy use. Among these, most have focused on operational energy use and none have analysed the effect of house size on the 
life cycle energy use in a systematic manner. This section reviews existing studies. These are described from those focusing on operational energy use to those considering life cycle requirements.

Multiple studies rely on large sample sizes of houses and households and collect a broad range of variables including characteristics such as household size, floor area, age, gender and occupation of the occupants, level of education, income as well as energy use. These studies then correlate the different variables to create regression models that identify the most significant ones. For example, Yohanis et al. [14] have evaluated the effect of household and house characteristics on the electricity use of dwellings in Northern Ireland. They found that electricity use is strongly correlated with floor area and increases on average by $49 \mathrm{kWh}(176.4 \mathrm{MJ})$ for every additional square meter of floor area. Another study by Guerra Santin et al. [12] evaluated energy use for space and hot water heating in Dutch dwellings by evaluating the effect of the occupants behaviours. Among the multiple variables considered is the floor area. Their study found that the useful floor area was again a good predictor of energy use: larger houses use more energy. In another study on increased thermal performance in Australia and the simultaneous construction of larger houses, Clune et al. [11] found that the additional heating and cooling demands required for the extra spaces offset a significant share of the energy and greenhouse gas emissions reductions achieved through increased thermal performance. These findings reproduce at a larger scale those of Wilson and Boehland [13] who compared small thermally inefficient houses in the USA to large efficient houses. The USA-based study found that these smaller houses use the same amount of energy as their larger, yet more efficient counterparts and calls for reduced house sizes for better energy and resource efficiency. All these studies highlight the significance of floor area and its effect on operational energy use but none considers embodied energy.

Fuller and Treloar [15] and Fuller and Crawford [16] have quantified the embodied, operational and user-transport energy requirements for different dwelling types around Melbourne. These studies consider both embodied and operational energy and use comprehensive system boundaries to quantify both. While they assess different dwelling types with different sizes, they rely on a very small sample size of different house sizes and these are built using different assemblies. Their studies do no therefore evaluate the relationship between house size and life cycle energy use. There is therefore a need to better understand this relationship in order to inform effective building energy efficiency regulations. 


\section{Quantifying the effect of house size on life cycle energy use}

144 This section describes the overall modelling approach used to address the aim of the study and the quantification algorithms used to estimate the bill of quantities and calculate life cycle embodied and operational energy use.

\subsection{Overall modelling approach}

In order to evaluate the relationship between house size and life cycle energy use, a large sample of house and household sizes is needed. Collecting the necessary data in order to conduct a life cycle energy analysis on existing houses (e.g. bill of material quantities) can be a prohibitive and time consuming task. There is also a concern regarding consistent data quality across the surveyed houses. Using a computer model can streamline the process, ensure a systematic approach and isolate key variables.

This study uses a case study house located in Melbourne, Australia. Typical construction assemblies are used to ensure a broad representativeness. The characteristics of the case study house are presented in Table 1. The case study is located in the Australian state of Victoria not only because it has the largest houses in Australia but also because Melbourne is the fastest growing city in Australia in terms of population, with an estimated population of 10 million by 2051 . It is therefore set to increase its housing stock in the coming decades [36]. Understanding the relationship between house size and life cycle energy use is therefore critical in this context.

The house is modelled using the advanced software tool developed by Stephan [37] and described in Stephan and Crawford [38]. The tool is capable of automatically modifying the dimensions of the house (width and depth), estimate the bill of quantities of each house size, vary the number of occupants and quantify its initial and recurrent embodied energy as well as operational energy use over any period of analysis. While the tool is also able to model multi-storey houses and apartment buildings as well as calculate life cycle water and greenhouse gas emissions, this was considered to be outside the scope of this paper. More details about the equations used in the tool are provided in Sections 3.2, 3.3, 3.4 and 3.5.

The tool starts with a $10 \times 10 \mathrm{~m}$ house and incrementally increases its width and depth until the maximum $14 \times 28 \mathrm{~m}$ dimensions. For each house size, 4 different occupancy levels are evaluated (2, 
1713,4 and 5 occupants). The total number of variations includes 9 widths $\times 10$ depths $\times 4$ household 172 sizes (=360 variations). These variations are based on typical dimensions of houses built by major 173 developers in Australia. The household sizes are representative of the most common households 174 living in detached houses according to the last Australian census [24]. Lone person households were 175 not considered as these typically reside in apartment units based on the same census data.

176 Similar floor areas that result from different combinations of width and depth (e.g. $10 \times 14 \mathrm{~m}$ and $14 \times$ $17710 \mathrm{~m}$ ) have both been evaluated because they result in different material quantities and therefore 178 embodied energy use. Apart from the geometrical dimensions of the house and the number of 179 occupants, all other variables in the model are kept constant. These include thermal performance, 180 building systems, building materials and embodied energy coefficients. This allows a consistent and 181 rigorous comparability of results and isolates the studied variables. A summary of the method is 182 presented in Figure 1. 


\begin{tabular}{ll}
\hline Characteristic & Value $(\mathrm{s})$ \\
\hline Width $(\mathrm{m})$ & $10,10.5,11,11.5,12,12.5,13,13.5,14$ \\
Depth $(\mathrm{m})$ & $10,12,14,16,18,20,22,24,26,28$ \\
Household size (number of occupants) & $2,3,4,5$ \\
Height $(\mathrm{m})$ & 3 \\
Location & Melbourne, Victoria, Australia \\
Period of analysis (years) & 50 \\
Structure type & Timber-framed, Reinforced Concrete Slab on \\
& ground \\
Façade & Brick veneer wall; 100 mm of fibreglass insulation; \\
& Double glazed aluminium-framed windows (30\% \\
Roof & window to wall ratio) \\
Flooring & Concrete tiles; 200 mm of fibreglass insulation \\
Internal walls & Carpet in bedrooms and living rooms; ceramic tiles \\
Average U-value of the building $\left(\mathrm{W} /\left(\mathrm{m}^{2} \cdot \mathrm{K}^{-}\right)\right)$ & in wet areas \\
Ventilation rate during 5 hours $/ \mathrm{day}\left(\mathrm{ach}{ }^{-1}\right)$ & 10 mm painted plasterboard \\
Operational energy sources & O.58 \\
\hline
\end{tabular}

Note: characteristics in italic are varied, eff $=$ efficiency, COP $=$ coefficient of performance.

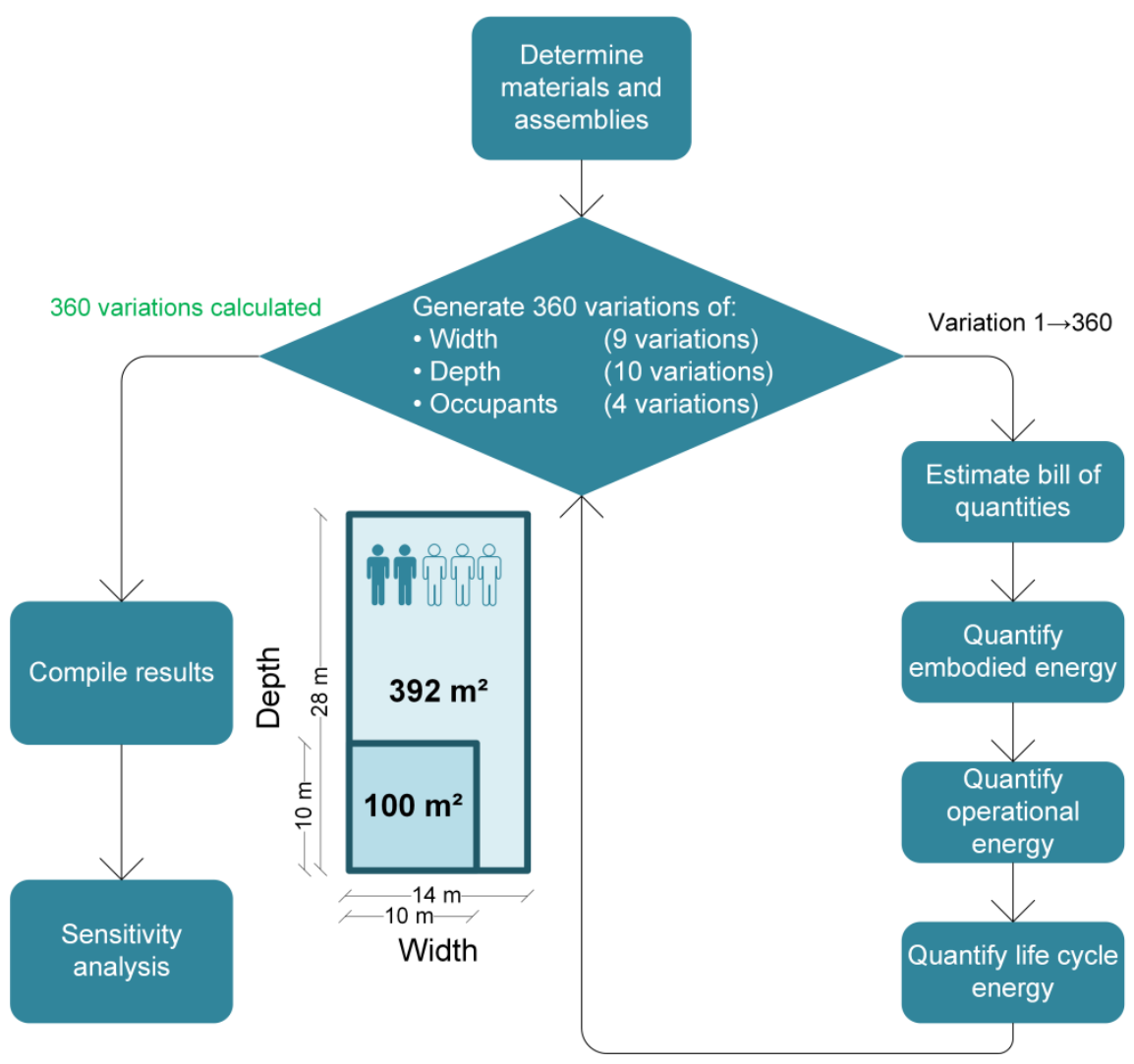

Figure 1: Flowchart diagram of the method 
The bill of material quantities is central to the calculation of embodied energy requirements. It is

190

$$
L_{p, w}=G F A \times \alpha_{G F A \rightarrow U F A} \times L_{p, w \rightarrow U F A}
$$

Where (final results are indicated in bold):

205

$G F A=$

Gross floor area of the building in $\mathrm{m}^{2}$;

$206 w=$

Width of the house in $\mathrm{m}$;

207

$d=$

Depth of the house in $\mathrm{m}$;

$208 N S=$

Number of storeys of the house (=1 storey in this case); 
Roof area in $\mathrm{m}^{2}$; figures from [40]).

The number of doors and heating and cooling delivery units is based on the average number of rooms in the house which is obtained by dividing the usable floor area by the average room size (in this case $15 \mathrm{~m}^{2}$ ). The amount of steel and concrete in the raft foundation is calculated based on a thickness of $30 \mathrm{~cm}$ and a reinforcement rate of $100 \mathrm{~kg} / \mathrm{m}^{3}$.

These equations result in quantities that deviate at most by $\pm 10 \%$ from actual bill of quantities for a typical Australian detached house as demonstrated in Stephan [37]. The only exception is the number of doors which depends heavily on the spatial layout of the house and its open plan nature. In addition to the validation conducted in Stephan [37], ten random houses with varying floor areas where selected from the website of one of Australia's major developers. For each of these houses, the area of outer and inner walls were derived from floor plans and compared to those produced by the software for a house of the same floor area. The estimated quantities were within $\pm 5 \%$ of the actual areas, further validating the estimation. materials per functional unit of assembly. For example, the first house variation $(10 \times 10 \mathrm{~m})$ contains 
$150 \mathrm{~m}^{2}$ of internal walls. Each $1 \mathrm{~m}^{2}$ of internal walls contains the required ties, bolts, studs, proportion of bottom and top plate, noggins, bracing, plasterboard panels and water-based paint. The total quantity for each material is equal to $150 \times$ the quantity of this material per $\mathrm{m}^{2}$ of internal wall. In addition, defining whole assemblies in the software allows a detailed representation of the construction technology used and does not discard minor elements and materials as is often the case in building life cycle assessment studies. The next section describes how material quantities are converted to embodied energy figures.

\subsection{Quantifying embodied energy use}

245 Embodied energy represents the sum of all energy inputs for the production of building materials across their supply chains, including non-material services. Embodied energy can be broken down into two components: initial and recurrent embodied energy. The first represents the total embodied energy of the house as-built, prior to its use by the first household. The second takes into account the embodied energy associated with the replacement of building materials across the period of analysis (50 years in this study).

To date, the most reliable and comprehensive technique to quantify embodied energy is hybrid analysis that combines industrial process data (e.g. about the energy intensity of manufacturing processes) and economic input-output data at the sectorial level (e.g. the average energy intensity of the steel industry in GJ/current unit). The input-output-based hybrid analysis developed by Treloar [41] and validated by Crawford [42] combines these two datasets in the most reliable manner, by avoiding double counting, ensuring comprehensive system boundaries and using the most robust data where possible. Studies [24, 43-45] have shown that relying on hybrid analysis can produce embodied energy intensities that are 2 to 4 times higher compared to using process data which is the most commonly used.

This paper relies on the comprehensive input-output-based hybrid analysis to quantify embodied energy. The quantities of materials in each house size variation (see Section 3.2) are multiplied by embodied energy coefficients compiled by Treloar and Crawford [46]. An additional amount of energy is then added to the total to account for non-material processes, such as insurance and advertising. Materials are replaced according to average service lives which are based on Ding [47] and NAHB and Bank of America [48]. The recurrent embodied energy associated with each material replacement 
is calculated by multiplying the quantity of materials replaced by its embodied energy coefficient and adding energy inputs of non-material processes associated with this particular material. The life cycle embodied energy for each house size is quantified as per Equation 8.

269

$$
L C E E_{h}=\sum_{m=1}^{M}\left(Q_{m} \times E C_{m}\right)+\left(T E R_{r b}-\sum_{m=1}^{M} T E R_{m}\right) \times C_{h}
$$

$$
+\sum_{m=1}^{M}\left[\left\lfloor\frac{P O A}{S L_{m}}-1\right\rfloor \times\left[\left(Q_{m} \times E C_{m}\right)+\left(T E R_{r b}-T E R_{m}-T E R_{i \neq m}\right) \times C_{m}\right]\right]
$$

270

Where: $L C E E_{h}=$ Life cycle embodied energy of house $h$, in GJ; $Q_{m}=$ Quantity of material $m$ in the house, in $\mathrm{t}, \mathrm{m}^{3}, \mathrm{~m}$ or another functional unit; $E C_{m}=$ Hybrid energy coefficient of material $m$, in $\mathrm{GJ}$ per functional unit; $T E R_{r b}=$ Total energy requirements of the residential building sector $r b$, in GJ per AUD; $T E R_{m}=$ Total energy requirements of the input-output pathways representing the material production processes for which process data is available, in GJ per AUD; $C_{h}=$ Cost of the house $h$ in AUD; POA $=$ Period of analysis, in years; $S L_{m}=$ Average service life of the material $m$, in years; $T E R_{i \neq m}=$ Total energy requirements of all input-output pathways not associated with the installation or production process of material $m$, in GJ per AUD; and $C_{m}=$ Cost of the material $m$ in AUD.

\subsection{Quantifying operational energy use}

The energy used by occupants to maintain indoor thermal comfort, for lighting, cooking, hot water and appliances represents operational energy. In this study, thermal energy is quantified using the heat transfer coefficient of envelope elements, ventilation rates and heating/cooling degree hours. The model described in Stephan [37] uses steady-state thermodynamic equations and relies on indoor comfort temperatures of $20^{\circ} \mathrm{C}$ and $26^{\circ} \mathrm{C}$ for heating and cooling, respectively. The degree hours calculated for Melbourne's climate (21919 K.h for heating and $2170 \mathrm{~K} \cdot \mathrm{h}$ for cooling) take into account solar and free internal gains by adapting the balance temperature. While using dynamic thermal modelling through a third party software tool (e.g. EnergyPlus), that takes into account thermal mass among other aspects, could generate more accurate results, the steady-state approach is sufficient within the scope of this paper. Indeed, since this study aims to understand the relationship between house size and life cycle energy use, the consistency of the quantification approach for all variations is the most important aspect (rather than the accuracy of the energy demand estimation). In addition, using advanced simulation software does not systematically result in a more accurate 
quantification of thermal energy use, as demonstrated by a number of studies, such as Williamson et al. [49].

294 Energy for cooking and appliances is modelled using average intensities that are derived from DEWHA [50]. The hot water energy demand is based on a daily hot water use of $70 \mathrm{~L} /$ capita and an average annual temperature difference between mains water and final hot water of $47^{\circ} \mathrm{C}$. This produces results that are consistent with the averages reported in [50] for Victoria. Lighting is calculated based on the floor area of the house while hot water, appliances and cooking are calculated based on the number of occupants.

The annual operational energy demand is assumed to be constant over the 50 years period of analysis. The life cycle operational energy demand is calculated as per Equation 9, by converting each energy use to primary energy terms by considering the efficiency of the system and the energy source, summing all operational energy demands and multiplying the total by the period of analysis. Primary energy conversion factors of 3.4 for electricity and 1.4 for gas are used and are based on Treloar [51].

306

$$
L C O P E_{h}=P O A \times \sum_{e=1}^{E}\left(\frac{O P E_{e}}{\eta_{e}} \times P E F_{e}\right)
$$

Where: $L C O P E_{b}=$ Life cycle primary operational energy of the house $h$ in GJ; $P O A=$ Period of analysis in years; $O P E_{e}=$ Annual final operational energy demand of the end-use $e$ in GJ; $\eta_{e}=$ Average efficiency of the system used for end-use $e$; and $P E F_{e}=$ Primary energy conversion factor of the end-use e based on the energy source.

\subsection{Quantifying life cycle energy use}

312 The life cycle energy demand of each house variation $\left(L C E_{h}\right)$ is the sum of its life cycle embodied energy $\left(L C E E_{h}\right)$ and its life cycle operational energy $\left(L C O P E_{h}\right)$ over the period of analysis (50 years).

\section{Results}

315 This section presents the results of the study. The relationship between house size and life cycle energy profile is first described before assessing the significance of the functional unit and embodied energy. A sensitivity analysis of the results to uncertainty in data is finally conducted. 


\subsection{The effect of house size on the life cycle energy profile}

319

320

321

322

323

324

325

Figure 2 depicts the life cycle energy demand of each end-use (embodied and operational), for each house size variation. Only heating, cooling and lighting operational energy demands are represented as energy use for hot water, appliances and cooking are assumed to be solely determined by the number of occupants. The noise in the graph is due to the different bill of material quantities generated for houses with different proportions but similar gross floor area.

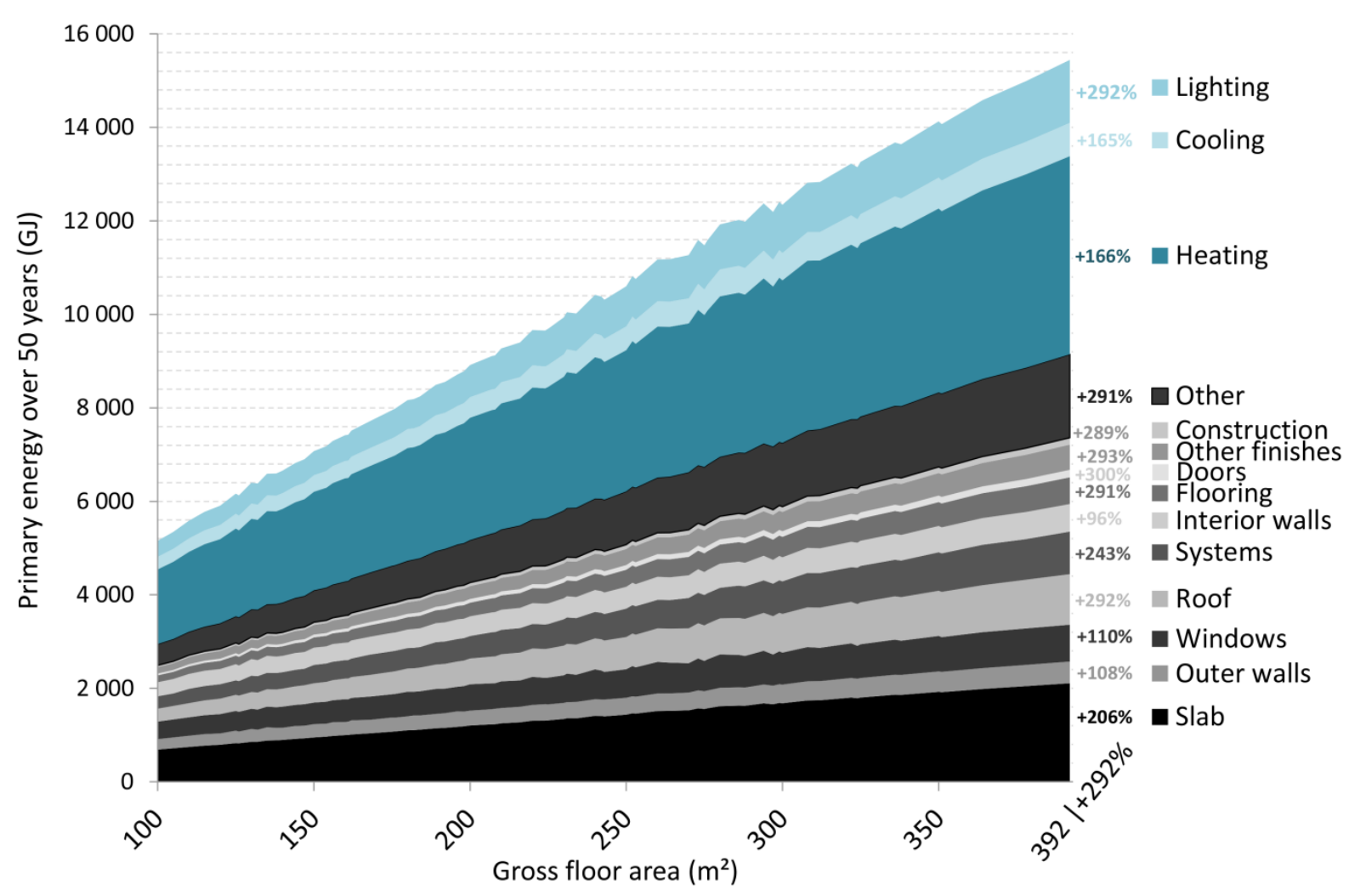

Figure 2: Effect of size on the life cycle energy demand of the house over 50 years, by use.

The life cycle energy demand of the largest variation (392 m²) is 15443 GJ, compared to 5156 GJ for the $100 \mathrm{~m}^{2}$ variation. The increase in life cycle energy use is therefore $+200 \%$ compared to $+292 \%$ in floor area. This shows that life cycle energy demand tends to be sublinearly correlated with house size. This implies that using a per square metre functional unit systematically flaws results as will be discussed in depth in Section 4.2. The life cycle embodied energy increases by $210 \%$ (in a similar manner for both initial and recurrent embodied energy) and operational energy by $185 \%$ (heating, cooling and lighting) for an increase of $292 \%$ in floor area. This reveals that embodied energy becomes systematically more significant as houses increase in size in comparison to operational energy. 
However, the increase in embodied energy is different for each assembly type. As a general trend, the embodied energy of horizontal assemblies seems to be almost linearly correlated with house size, e.g. flooring $(+293 \%)$, roof $(+292 \%)$ and slab $(+206 \%)$. In contrast, the embodied energy of vertical assemblies, e.g. outer walls, interior walls and windows increases by $\sim 110 \%$. This is due to the fact that the material intensity for different house sizes is not the same and larger houses require less vertical assemblies as room areas become larger. In other words, horizontal assemblies contribute more than vertical assemblies to the life cycle energy demand of larger houses compared to smaller houses using the exact same assemblies. The choice of horizontal assemblies becomes more critical for larger houses. Note that the 'other finishes', 'construction' and 'other' embodied energy categories are calculated on a per square metre basis and are therefore linearly correlated with floor area.

The heating and cooling demands increase by $166 \%$ and $165 \%$, respectively. This is because the heat transfer area is not a direct function of the floor area but also depends on the compactness of the building or its surface to volume ratio (as can be deduced from Equations 2-5). This means that heating and cooling increase at around $57 \%$ the rate of the floor area of the case study house. The Australian building energy efficiency regulation takes this into account and uses a so-called 'area adjustment factor' of $\sim 40 \%$ between a 100 and a $400 \mathrm{~m}^{2}$ house [52]. This factor seems to be slightly underestimating the effect of size. However, regulations or certifications that do not correct for house size could be systemically favouring larger houses by artificially making them achieve a better operational energy rating because they have a lower heating and cooling demand per square metre. This is of concern as a significant number of large detached houses have been built in Europe and certified as Passive Houses or low-energy houses. For example, out of 149 detached passive houses in French Speaking Belgium (including Brussels and Wallonia), 68 (46\%) have a floor area larger than $200 \mathrm{~m}^{2}$ and detached houses represent $34 \%$ of all certified passive house buildings, including apartment buildings, schools and others [53]. It is easier for larger houses to get certified while these systematically require more energy for heating, cooling, lighting than smaller houses built with the same assemblies. Also, these larger houses require a significant amount of additional embodied energy, notably for the additional insulation, as shown in Dahlstrøm et al. [54] and Stephan et al. [27]. Including house size in all energy efficiency regulations is therefore critical to ensure that net energy reductions do occur. 
This section has assessed the relationship between house size and life cycle energy demand in detail. The next section focuses on the significance of the functional unit used when comparing houses of different sizes.

\subsection{The importance of the functional unit}

Figures 3 and 4 show the effect of house size on total life cycle energy demand (including all operational energy end-use) per square metre and per capita, respectively. The values of life cycle energy use of the smallest and largest houses are indicated, as well as the percentage increase/decrease. Three main observations can be made.

Firstly, while the energy intensity per capita increases with house size at the same rate as the absolute energy demand, it decreases when expressed on a per square metre basis. Using a spatial functional unit fails to consider the size of the house and systematically favours larger houses. This is because the life cycle embodied energy demand and the thermal and lighting operational energy demands are sublinearly correlated with house size (see Section 4.1) and because the hot water, appliances and cooking energy demands are assumed to be solely associated with the number of occupants. A larger house with the same household size will therefore appear to be more energy efficient on a per square metre basis. This means that building energy efficiency regulations need to correct energy use for house size in order to avoid artificially decreasing the energy intensity per square metre of larger houses and making them look efficient while they result in a higher life cycle energy demand.

Secondly, because house size increases faster than energy use, relying on a spatial functional unit blurs the difference between the different houses. For instance, the difference between the life cycle energy use of a $100 \mathrm{~m}^{2}$ house with two or five occupants is $40 \%$ (112 GJ/m² compared to $80 \mathrm{GJ} / \mathrm{m}^{2}$ ) while the difference between two houses of $392 \mathrm{~m}^{2}$ with the same number of occupants is only $17 \%$ (52 GJ/m² compared to $47 \mathrm{GJ} / \mathrm{m}^{2}$ ). For increasing house sizes, using a spatial functional unit without any correction is not reliable. Thirdly, Figure 4 reveals the importance of lifestyle. Indeed, two occupants living in a $160 \mathrm{~m}^{2}$ house (point A) use a similar amount of energy ( 5 $100 \mathrm{GJ}$ ) over 50 years as three occupants living in a 260 $\mathrm{m}^{2}$ house (point $\mathrm{B}$ ) or four occupants living in a $392 \mathrm{~m}^{2}$ house (point $\mathrm{C}$ ). Expressing results on a per capita basis relates energy use back to the occupants and enables a comparison of different lifestyles 
by capturing the floor area per capita. Figure 4 also enables the comparison of energy use for the same floor area per capita. For instance, two occupants living in a $100 \mathrm{~m}^{2}$ house (50 $\mathrm{m}^{2} /$ capita) require $4009 \mathrm{GJ} /$ capita while four occupants living in a $200 \mathrm{~m}^{2}$ house (50 $\mathrm{m}^{2} /$ capita) require 3495 GJ/capita, revealing the increased efficiency of larger houses with a large number of occupants. Yet, since household size has been decreasing, large houses with large households are not often observed.

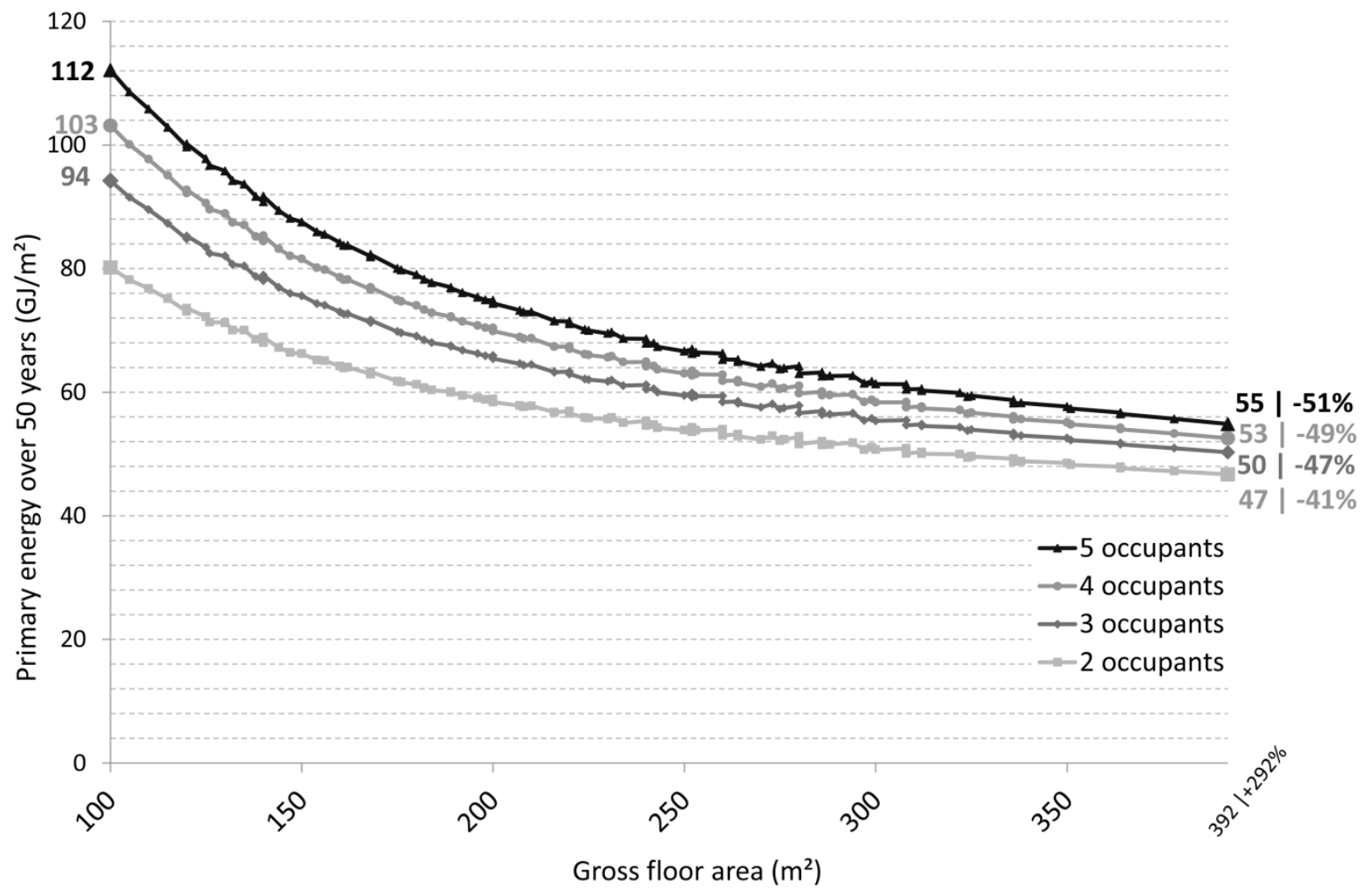

400 Figure 3: Effect of size and occupancy on the life cycle energy demand of the house over 50 years, per square metre. 


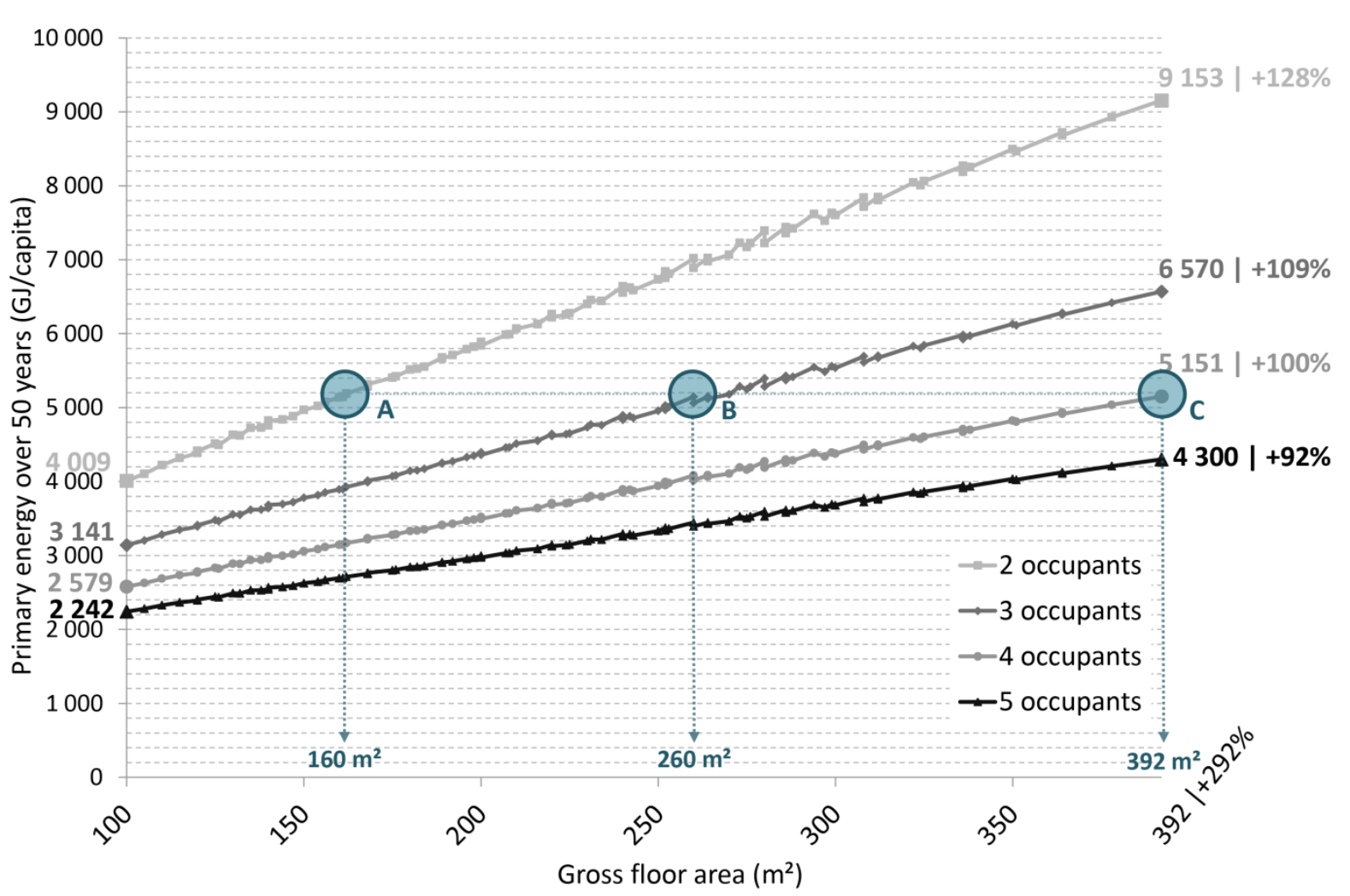

403 Figure 4: Effect of size and occupancy on the life cycle energy demand of the house over 50 years, 404 per capita.

\section{$405 \quad 4.3$ The significance of embodied energy}

Figure 5 shows the contribution of initial and recurrent embodied energy as well as life cycle operational energy to the total life cycle energy demand of the house, for different house sizes and number of occupants. Overall, embodied energy represents $26-50 \%$ of the total life cycle energy use. Note that for the $200 \mathrm{~m}^{2}$ house with two occupants, which is very close to the average floor area per capita in Australia $\left(100 \mathrm{~m}^{2} /\right.$ capita $\approx 94 \mathrm{~m}^{2}$ /capita, see Section 1$)$, embodied energy represents $44 \%$ of the total. This is much higher than the average $10-20 \%$ reported in major reviews of life cycle energy use in buildings and is due to the much wider system boundaries used in the quantification of embodied energy.

414 A very important aspect to consider is the temporal significance of each energy demand. While recurrent embodied energy and operational energy use take place over 50 years in this study, the initial embodied energy expenditure occurs once. Ongoing energy demands can be significantly reduced by relying on renewable energy sources and low embodied energy renewable materials. In parallel, the actual number of occupants in a house can fluctuate greatly over a building's life and the 
419 variability in operational energy use is therefore significant. Conversely, the greenhouse gas emissions associated with initial embodied energy cannot be reduced once the house has been erected. These have been highlighted by previous studies such as Säynäjoki et al. [55] who have dubbed them the 'carbon spike' in a building's life cycle. The environmental repercussions of these emissions are also likely to be more significant presently than in the future, as demonstrated by Kendall et al. [56] and Schwietzke et al. [57]. With initial embodied energy representing a growing share of the total as house size increases (up to $31 \%$ ) and resulting in large quantities of greenhouse gas emissions, it is critical to ensure that the size of the house is optimised and building materials are chosen to reduce initial embodied energy as much as possible.

428

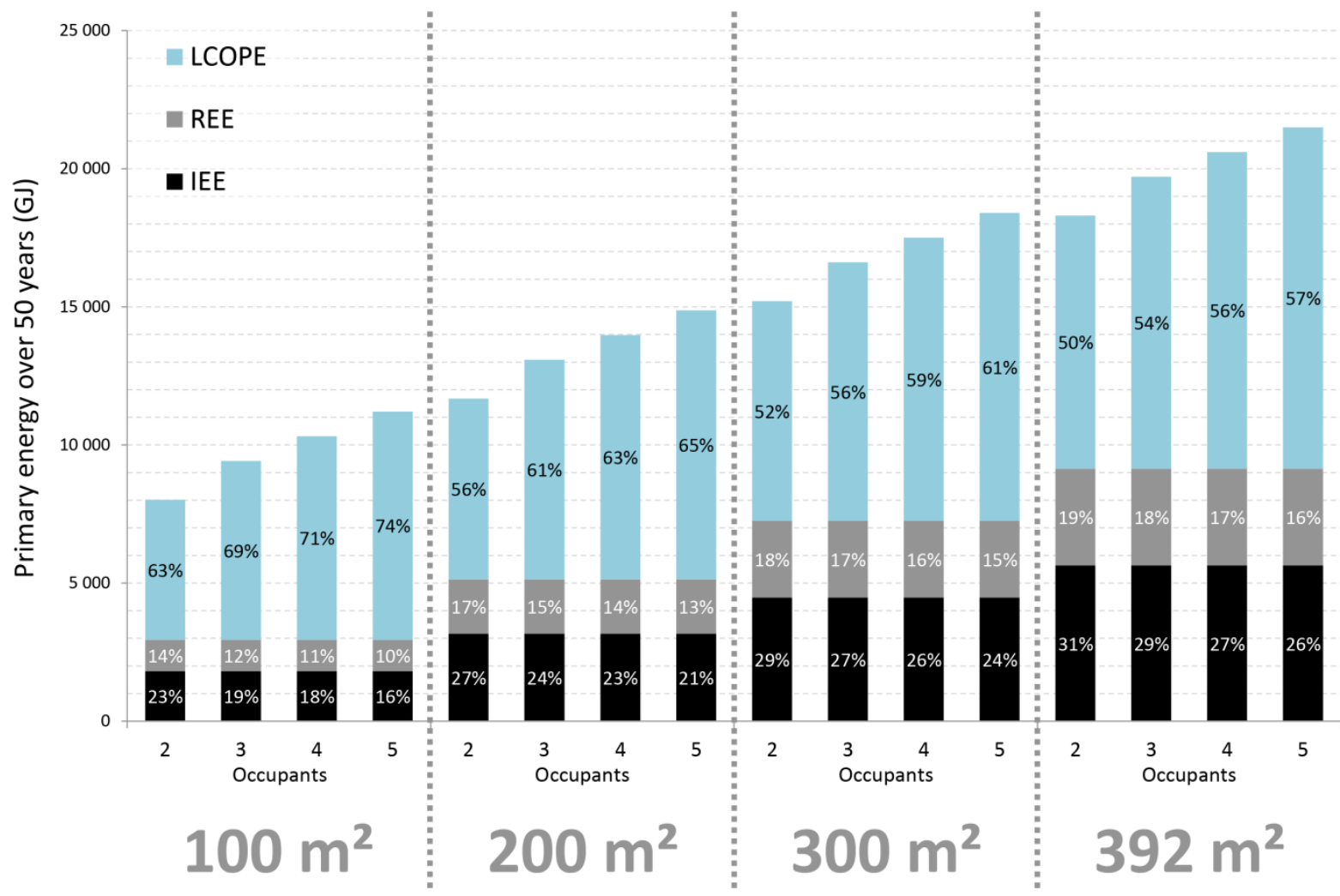

430 Figure 5: The contribution of embodied and operational energy to the life cycle energy demand of the house over 50 years, for selected house sizes and occupancy profiles. Note: IEE = initial embodied energy, REE = recurrent embodied energy and LCOPE = life cycle operational energy. Percentages may not sum due to rounding. 


\subsection{Sensitivity analysis}

435

The comparative nature of this study makes it less prone to being influenced by uncertainty in the data as all variations are equally affected. The sensitivity analysis is therefore necessary only when absolute energy demands are being compared, such as the contribution of embodied energy and operational energy to the life cycle energy demand of each variation.

In order to evaluate to what extent uncertainty in the data affects the breakdown of the life cycle energy demand, a sensitivity analysis is performed by varying embodied and operational energy by a set potential error margin. The uncertainty for embodied energy is calculated using a margin of $\pm 20 \%$ for process data and $\pm 50 \%$ for input-output data as per Crawford [24]. This uncertainty is propagated throughout the model from the material embodied energy coefficients calculations. The overall resulting uncertainty margin for embodied energy is $\pm 39.5 \%$. For operational energy use, user behaviour as well as the assumption that the entire space is heated and cooled, regardless of the occupancy level, result in an uncertainty range of $\pm 20 \%$. This is based on previous studies on uncertainty and variability of operational energy use (e.g. [58, 59]).

Figure 6 shows the contribution of each of the life cycle embodied energy demand (dark) and the life cycle operational energy demand (light) to the total, for each house size, and for each combination of minimum and maximum uncertainty value. The sensitivity analysis shows that uncertainty in the data can significantly affect the contributions of each of the embodied and operational energy use. The life cycle embodied and operational energy demands can represent $15-64 \%$ and $36-85 \%$ of the total, respectively. These values should be seen as extreme boundaries with a relatively small likelihood of occurrence. The average values depicted in Figure 5 are representative of most cases. Regardless of uncertainty in the data, it should be noted that embodied energy, which is often thought to represent $10-20 \%$ of the life cycle energy demand over 50 years, represents at least $15 \%$ (in a $100 \mathrm{~m}^{2}$ house with 5 occupants and considering the highest possible operational energy demand and the lowest possible embodied energy demand) and up to $64 \%$ of the demand. Another critical point is the very high level of uncertainty when it comes to the contribution of each life cycle energy demand to the total. This is further discussed in Section 5. 

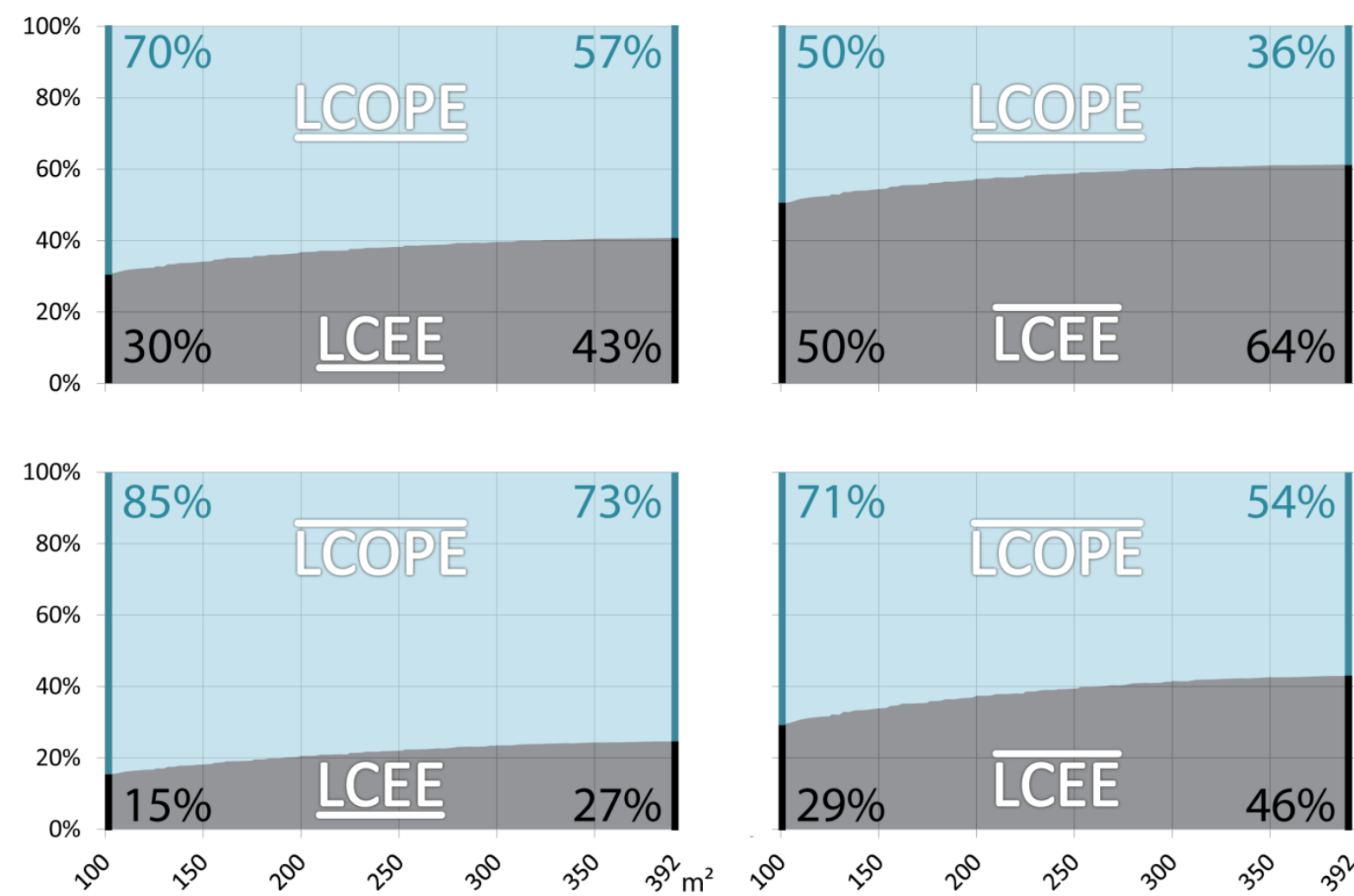

Figure 6: Sensitivity of the contribution of life cycle embodied and operational energy use to uncertainty in the data, by house size. Note: LCEE = life cycle embodied energy, LCOPE = life cycle

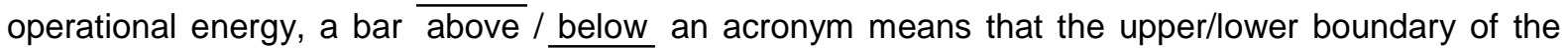
uncertainty range in considered.

\section{Discussion}

This paper has evaluated for the first time the relationship between house size and life cycle energy demand while using a systematic approach, comprehensive system boundaries for embodied energy and primary operational energy use over 50 years. Previous studies on house size and energy use either focus on operational energy or do not consider large sample size of different house sizes (see Section 2 for details). Results show that larger house sizes result in a higher overall life cycle energy demand through the increase of both operational and embodied energy. Both operational and embodied energy are sublinearly correlated with house size. The use of a spatial functional unit (e.g. $\mathrm{MJ} / \mathrm{m}^{2}$ ) to express energy efficiency therefore systematically favours larger houses, even for embodied energy. The latter was found to be significant and represents $26-50 \%$ of the total across all 360 variations. These results can inform future building energy efficiency regulations in Australia and in other countries. 
480 Most existing building energy efficiency regulations do not take house size or floor area into account.

481 This study has shown that house size is a critical factor affecting both embodied and operational life 482 cycle energy use. Different life cycle energy efficiency levels can therefore be used for different house 483 sizes with stricter limits for larger houses in order to favour more compact dwelling forms that use less 484 materials. Also different limits can be used for different assembly types depending on the house size as horizontal assemblies become more significant than vertical assemblies for an increasing floor area (see Figure 2). These limits should however take into account the number of occupants the house is designed for. As shown in Figure 4, for the same floor area per capita, larger houses are more energy efficient. Including the designed floor area per capita in the regulation process can help produce optimal forms of housing that are best tailored to the number of occupants that use them.

Including embodied energy

This study has shown that embodied energy can represent $24-50 \%$ of the life cycle energy use in an Australian context. This only confirms the findings of a number of existing studies (inter alia $[8,9,60]$ ) that show that embodied energy cannot be excluded from building energy efficiency regulations if these are to be effective. With the increased energy efficiency of dwellings, embodied energy is set to become even more significant $[27,54]$.

Embodied energy should be calculated with the most comprehensive method available: input-outputbased hybrid analysis. There is therefore a critical need to develop reliable, location-specific and open-access databases that allow practitioners to robustly conduct a life cycle energy analysis of a building. The current use of process data for most building life cycle assessments can significantly underestimate embodied energy [61], by up to $87 \%$ at the product level [42], and up to $77 \%$ at the whole building level [24, 43, 44]. Ideally, multi-regional input-output-based hybrid data should be compiled and made available for all on online platforms such as the Industrial Ecology Virtual Laboratory (IELab) in Australia [62]. 


\section{Relying on different functional units}

505 One of the major flaws of current building energy efficiency regulations around the world is their reliance on a single unit to measure efficiency: $\mathrm{kWh} / \mathrm{m}^{2}$ or $\mathrm{MJ} / \mathrm{m}^{2}$. This study has demonstrated that a spatial functional unit systematically flaws the results by favouring larger dwellings. While it is believed that a spatial functional unit allows the comparison of buildings with different areas, this study clearly disproves that. There are two main repercussions to that. Firstly, existing regulations systematically favour larger buildings because both thermal energy use and embodied energy are sublinearly correlated with house size. Secondly, existing studies which rely on average energy use or embodied energy intensities per square metre to calculate embodied energy might be significantly under or overestimating energy use. Energy intensities cannot simply be used between different houses or buildings.

Different functional units are therefore needed to measure energy efficiency. As Calwell [22] indicated, having an absolute energy use indicator is the best way to measure the total associated environmental damage. This can be adjusted based on the size of the house and the number of occupants it is intended for. A spatial functional unit can also be used if it is corrected for size. The correction factors should be based on a broad analysis of existing buildings and their overall energy performance. Correction factors for embodied energy should be based on both house size and material composition. A significant amount of work is needed in this direction to produce reliable coefficients. Finally, a per capita functional unit would be ideal for post-occupancy monitoring. While post-occupancy monitoring can be too expensive to deploy for nationwide building energy efficiency regulation schemes, these can and should be an integral part of facultative certifications such as the Passive House certification. This would avoid that occupants living in certified buildings actually use more energy than others living in standard buildings.

\section{$527 \quad 5.2$ Beyond energy use}

528 While this study has focused on energy use because it is representative of broader environmental impacts, there are a number of other flows that should be taken into account to ensure a broad environmental assessment of house size. These include water, greenhouse gas emissions and material use. Since the software tool developed by Stephan [37] already generates these results, major figures are outlined below. For more information the calculation of life cycle water use and 
greenhouse gas emissions, refer to Stephan and Crawford [63] and Stephan and Crawford [38], respectively.

535

Life cycle embodied water and greenhouse gas emissions are sublinearly correlated with house size. They increase by 208\% (from $6347 \mathrm{~kL}$ to $19559 \mathrm{~kL}$ ) and 210\% (from $176967 \mathrm{kgCO}_{2}$-e to 549187 $\left.\mathrm{kgCO}_{2}-\mathrm{e}\right)$ for a $292 \%$ increase in gross floor area, respectively. Since operational water is calculated on a per capita basis in the model, it is not related to house size. It is also important to note that embodied water and greenhouse gas emissions represent $32-78 \%$ and $21-45 \%$ of the total. Operational greenhouse gas emissions associated with heating, cooling and lighting, increase by $192 \%$ (from $153107 \mathrm{kgCO}_{2}$-e to $446899 \mathrm{kgCO}_{2}-\mathrm{e}$ ) for a $292 \%$ increase in gross floor area. The increase in quantities of aluminium, glass, timber and steel is $111 \%$ (from $448 \mathrm{~kg}$ to $944 \mathrm{~kg}$ ), $135 \%$ (from $1724 \mathrm{~kg}$ to $4060 \mathrm{~kg}$ ), 117\% (from $87138 \mathrm{~kg}$ to $188801 \mathrm{~kg}$ ) and 187\% (from $5086 \mathrm{~kg}$ to 14074 $\mathrm{kg}$ ), respectively. This preliminary analysis shows that for all other indicators, the findings hold true: using a spatial functional unit favours larger houses and embodied requirements are significant.

\subsection{Limitations and future research}

As in any scientific study, a number of limitations can affect the results. Firstly, using a computer model to estimate bills of material quantities and calculate embodied and operational energy use can result in a significant level of uncertainty. Collecting actual bills of material quantities and postoccupancy operational energy figures would significantly improve the robustness of the results. This however would require a huge amount of resources. Secondly, this paper uses a case study house and results are valid only for the studied house. Other house types and building materials might result in different findings. Thirdly, this study has assumed that the height of the house remains constant across different sizes. However, Wilson and Boehland [13] state that larger houses tend to have a higher height which entails more material and thermal energy use. Increasing the height of the house from $3 \mathrm{~m}$ to $4 \mathrm{~m}$ for the $392 \mathrm{~m}^{2}$ house increases its life cycle embodied energy by $6.8 \%$ and its life cycle operational energy by $14.7 \%$. These same quantities still increase by $220 \%$ (compared to $210 \%$ for $3 \mathrm{~m}$ of height) and $234 \%$ (compared to $175 \%$ for $3 \mathrm{~m}$ of height) for a $292 \%$ in house size, respectively. The height of the house seems to affect the findings, notably the correlation of thermal and lighting energy use with house size. It is also important to verify if the increased quantity of furniture in larger houses offsets the increased material efficiency. More research is needed in this 
regard. Finally, this paper investigated the effect of house size on life cycle energy use, while most findings should be applicable to other building types, a thorough investigation of the effect of floor area and building size on the life cycle resource requirements of different buildings types would provide useful insights that can further inform environmental building regulations.

\section{Conclusion}

With a forecasted increase in the global urban population, it is essential that future dwellings are designed and used with minimal environmental impacts. Large houses with small households should be avoided to limit these impacts. This study has quantified the relationship between life cycle energy demand and house size, for different household sizes. It shows that future building energy efficiency regulations should take embodied energy and house size into account in order to ensure actual reductions in the life cycle energy demand. These regulations should rely on multiple functional units and move away from a single spatial functional unit (e.g. $\left.\mathrm{MJ} / \mathrm{m}^{2}\right)$ that was shown to systemically favour large houses. Failing to incorporate embodied energy and house size into building energy efficiency regulations can lead to a paradoxical increase in total life cycle energy use and associated environmental impacts when building so-called 'energy efficient' large detached houses.

\section{Acknowledgements}

This research is funded by the Australian Research Council under the Discovery Project DP150100962.

\section{References}

[1] NOAA. State of the Climate: Global Analysis for December 2014. National Climatic Data Center, Available from http://www.ncdc.noaa.gov/sotc/global/2014/12, 2015 (Accessed 19 January 2015) [2]
IEA.
Sustainable
Buildings,
Available
from http://www.iea.org/topics/energyefficiency/subtopics/sustainablebuildings/, 2015 (Accessed December 15th 2015)

[3] Anderson JE, Wulfhorst G, Lang W. Energy analysis of the built environment-A review and outlook. Renewable and Sustainable Energy Reviews. 2015;44:149-58.

[4] IPCC. Climate change 2014: mitigation of climate change. Contribution of working group III to the fifth assessment report of the intergovernmental panel on climate change. In: Edenhofer O, PichsMadruga R, Sokona Y, Minx JC, Farahani E, Kadner S, et al., editors. Cambridge: Cambridge University Press; 2014. 
592 [5] Perez-Lombard L, Ortiz J, Pout C. A review on buildings energy consumption information. Energ 593 Buildings. 2008;40:394-8.

594 [6] ABCB. Building Code of Australia (BCA) 2011. Australia: Australian Building Codes Board; 2011.

595 [7] EC. Directive 2010/31/EU of the European Parliament and the Council of the European Union of 596 the 19 May 2010 on the Energy Performance of Buildings. Official Journal of the European 597 Communities. Brussels: European Parliament and the Council of the European Union; 2010. p.23.

598 [8] García-Casals X. Analysis of building energy regulation and certification in Europe: their role, 599 limitations and differences. Energ Buildings. 2006;38:381-92.

600 [9] Szalay AZ-Z. What is missing from the concept of the new European Building Directive? Building 601 and Environment. 2007;42:1761-9.

602 [10] Stephan A, Crawford RH, de Myttenaere K. Towards a comprehensive life cycle energy analysis 603 framework for residential buildings. Energ Buildings. 2012;55:592-600.

604 [11] Clune S, Morrissey J, Moore T. Size matters: House size and thermal efficiency as policy 605 strategies to reduce net emissions of new developments. Energy Policy. 2012;48:657-67.

606 [12] Guerra Santin O, Itard L, Visscher H. The effect of occupancy and building characteristics on 607 energy use for space and water heating in Dutch residential stock. Energ Buildings. 2009;41:1223-32.

608 [13] Wilson A, Boehland J. Small is Beautiful U.S. House Size, Resource Use, and the Environment. J 609 Ind Ecol. 2005;9:277-87.

610 [14] Yohanis YG, Mondol JD, Wright A, Norton B. Real-life energy use in the UK: How occupancy and 611 dwelling characteristics affect domestic electricity use. Energ Buildings. 2008;40:1053-9.

612 [15] Fuller R, Treloar GJ. The Influence of Housing Size, Style and Location on Energy and 613 Greenhouse Gas Emissions. Proceedings Solar 2004: Life, The Universe and Renewables. Australia: 614 Australia and New Zeland Solar Energy Society (ANZSES); 2004.

615 [16] Fuller R, Crawford R. Impact of past and future residential housing development patterns on 616 energy demand and related emissions. Journal of Housing and the Built Environment. 2011;26:16561783.

618 [17] ABS. 8752.0-Feature article: average floor area of new residential buildings. Canberra: Australian 619 Bureau of Statistics; 2013.

620 [18] U.S. Census Bureau. American housing survey for the United States: 2013. Washington: United 621 States Census Bureau; 2013.

622 [19] NAHB. Spaces in New Homes. National Association of Home Builders, Available from 623 https://www.nahb.org/en/research/housing-economics/special-studies/spaces-in-new-homes-

624 2013.aspx, 2013 (Accessed December 15th 2015)

625 [20] Insee. Les logements en 2006. Institut national de la statistique et des études économiques, 626 Available from http://www.insee.fr/fr/themes/document.asp?ref id=ip1202, April 2015, 2008 627 (Accessed December 15th 2015)

628 [21] Insee. Les conditions de logement fin 2013. Institut national de la statistique et des études 629 économiques, Available from http://www.insee.fr/fr/mobile/etudes/document.asp?ref id=ip1546, April 630 2015, 2015 (Accessed December 15th 2015) 
[22] Calwell C. Is efficient sufficient? The case for shifting our emphasis in energy specifications to progressive efficiency and sufficiency. Stockholm: European Council for an Energy Efficient Economy; 2010.

634 [23] ABS. Article: Larger dwellings, smaller households. Australian Social Trends 2007. Canberra: Australian Bureau of Statistics; 2007. p.10.

636 [24] Crawford RH. Life cycle assessment in the built environment. London: Spon Press; 2011.

637 [25] Fay R, Treloar G, lyer-Raniga U. Life-cycle energy analysis of buildings: a case study. Build Res 638 Inf. 2000;28:31-41.

639 [26] Stephan A, Crawford $\mathrm{RH}$, de Myttenaere K. Multi-scale life cycle energy analysis of a low-density 640 suburban neighbourhood in Melbourne, Australia. Building and Environment. 2013;68:35-49.

641 [27] Stephan A, Crawford RH, de Myttenaere K. A comprehensive assessment of the life cycle energy 642 demand of passive houses. Appl Energ. 2013;112:23-34.

643 [28] Cabeza LF, Rincón L, Vilariño V, Pérez G, Castell A. Life cycle assessment (LCA) and life cycle 644 energy analysis (LCEA) of buildings and the building sector: A review. Renewable and Sustainable 645 Energy Reviews. 2014;29:394-416.

646 [29] Chau CK, Leung TM, Ng WY. A review on Life Cycle Assessment, Life Cycle Energy Assessment 647 and Life Cycle Carbon Emissions Assessment on buildings. Appl Energ. 2015;143:395-413.

648 [30] Karimpour M, Belusko M, Xing K, Bruno F. Minimising the life cycle energy of buildings: Review 649 and analysis. Building and Environment. 2014;73:106-14.

650 [31] Ramesh T, Prakash R, Shukla KK. Life cycle energy analysis of buildings: An overview. Energ 651 Buildings. 2010;42:1592-600.

652 [32] Junnila S. The environmental impact of an office building throughout its life cycle [PhD thesis]. 653 Espoo: Helsinki University of Technology Construction Economics and Management; 2004.

654 [33] Allacker K. Sustainable building. The development of an evaluation method [Ph.D. thesis]. 655 Leuven: Katholieke Universiteit Leuven; 2010.

656 [34] Oregi X, Hernandez P, Gazulla C, Isasa M. Integrating Simplified and Full Life Cycle Approaches 657 in Decision Making for Building Energy Refurbishment: Benefits and Barriers. Buildings. 2015;5:35465880.

659 [35] Winistorfer P, Chen Z, Lippke B, Stevens N. Energy consumption and greenhouse gas emissions 660 related to the use, maintenance, and disposal of a residential structure. Wood and Fiber Science. $6612007 ; 37: 128-39$.

662 [36] Victorian Government. Victoria in future. Population and household projections to 2051. 663 Melbourne: Victorian government; 2014. p.16.

664 [37] Stephan A. Towards a comprehensive energy assessment of residential buildings. A multi-scale 665 life cycle energy analysis framework [Ph.D. thesis]. Brussels: Université Libre de Bruxelles and The 666 University of Melbourne; 2013.

667 [38] Stephan A, Crawford RH. A multi-scale life-cycle energy and greenhouse-gas emissions analysis 668 model for residential buildings. Archit Sci Rev. 2014;57:39-48.

669 [39] Fay R. Comparative life cycle energy studies of typical Australian suburban dwellings. Australia: 670 University of Melbourne; 1999. 
671 [40] Du Bellay J-C, Gauzin-Mueller D, Hoyet R, Zacek M. Neufert. Paris: Dunod; 2006.

672 [41] Treloar GJ. Extracting embodied energy paths from input-output tables: towards an input-output673 based hybrid energy analysis method. Econ Systems Res. 1997;9:375-91.

674 [42] Crawford $\mathrm{RH}$. Validation of a hybrid life-cycle inventory analysis method. J Environ Manage. 675 2008;88:496-506.

676 [43] Crawford R, Stephan A. The significance of embodied energy in certified passive houses.

677 ICCBM 2013: International Conference on Construction and Building Materials. Copenhagen: World 678 Academy of Science, Engineering and Technology; 2013. p.473-9.

679 [44] Stephan A, Stephan L. Reducing the total life cycle energy demand of recent residential buildings 680 in Lebanon. Energy. 2014;74:618-37.

681 [45] Wiedmann TO, Suh S, Feng K, Lenzen M, Acquaye A, Scott K, et al. Application of Hybrid Life 682 Cycle Approaches to Emerging Energy Technologies - The Case of Wind Power in the UK. Environ 683 Sci Technol. 2011;45:5900-7.

684 [46] Treloar GJ, Crawford RH. Database of embodied energy and water values for materials. 685 Melbourne: The University of Melbourne; 2010.

686 [47] Ding G. The development of a multi-criteria approach for the measurement of sustainable 687 performance for built projects and facilities [Ph.D. thesis]. Sydney: University of Technology; 2004.

688 [48] NAHB, Bank of America. Study of life expectancy of home materials. In: Jackson J, editor. 689 Washington DC: National Association of Home Builders; 2007. p.19.

690 [49] Williamson T, Soebarto V, Radford A. Comfort and energy use in five Australian award-winning 691 houses: regulated, measured and perceived. Build Res Inf. 2010;38:509-29.

692 [50] DEWHA. Energy use in the Australian residential sector 1986-2020. Canberra: Department of the 693 Environment, Water, Heritage and the Arts; 2008.

694 [51] Treloar GJ. A comprehensive embodied energy analysis framework [Ph.D. Thesis]. Geelong: 695 Deakin University; 1998.

696 [52] Delsante A. Is the new generation of building energy rating software up to the task? - a review of 697 accurate. ABCB Conference 'Building Australia's Future 2005'. Surfers Paradise2005.

698 [53] Plate-forme Maison Passive. Inventaire, Available from 699 http://www.maisonpassive.be/spip.php?page=0 inventaire, 14/12/2015, 2015 (Accessed December $\left.70018^{\text {th }} 2015\right)$

701 [54] Dahlstrøm O, Sørnes K, Eriksen ST, Hertwich EG. Life cycle assessment of a single-family 702 residence built to either conventional- or passive house standard. Energ Buildings. 2012;54:470-9.

703 [55] Säynäjoki A, Heinonen J, Junnila S. A scenario analysis of the life cycle greenhouse gas 704 emissions of a new residential area. Environ Res Lett. 2012;7:034037.

705 [56] Kendall A, Chang B, Sharpe B. Accounting for Time-Dependent Effects in Biofuel Life Cycle 706 Greenhouse Gas Emissions Calculations. Environ Sci Technol. 2009;43:7142-7.

707 [57] Schwietzke S, Griffin WM, Matthews HS. Relevance of Emissions Timing in Biofuel Greenhouse 708 Gases and Climate Impacts. Environ Sci Technol. 2011;45:8197-203.

709 [58] Pettersen TD. Variation of energy-consumption in dwellings due to climate, building and 710 inhabitants. Energ Buildings. 1994;21:209-18. 
711 [59] Juodis E, Jaraminiene E, Dudkiewicz E. Inherent variability of heat consumption in residential 712 buildings. Energ Buildings. 2009;41:1188-94.

713 [60] Blengini GA, Di Carlo T. The changing role of life cycle phases, subsystems and materials in the 714 LCA of low energy buildings. Energ Buildings. 2010;42:869-80.

715 [61] Majeau-Bettez G, Strømman AH, Hertwich EG. Evaluation of process- and input-output-based life 716 cycle inventory data with regard to truncation and aggregation issues. Environ Sci Technol. $717 \quad 2011 ; 45: 10170-7$.

718 [62] Wiedmann T, Crawford R, Seo S, Giesekam J. The Industrial Ecology Virtual Laboratory and its 719 application to sustainability and environmental engineering - the case of low carbon living2013.

720 [63] Stephan A, Crawford $\mathrm{RH}$. A comprehensive life cycle water analysis framework for residential 721 buildings. Build Res Inf. 2014;42:685-95. 